\title{
"SAMPLE RECOMMENDATIONS (GROUPS OF PARENTS TO PREVENT AND OVERCOME THE FAILURE OF THE STUDENT)"
}

\section{Davronov Pirnazar Ziyatovich}

Professor of the Department ofPedagogy, Psychology and Educational Technologies of the Samarkand Regional Center forAdvanced Training and Retrainingof Public Education Workers, Uzbekistan.

\begin{abstract}
:
The article describes the recommendations of classroom teachers to parents on the prevention and elimination of the causes that negatively affect the learning of students.
\end{abstract}

Keywords:

Class teacher, parents, students, reading, academic performance, academic failure, mind, preventing and overcoming.

Article Received: 18 October 2020, Revised: 3 November 2020, Accepted: 24 December 2020

\section{INTRODUCTION}

Professor Yu.K.Babansky and his students studied a set of reasons that negatively affect the teaching of students. For these reasons, we present our recommendations for communicating with parents of students individually and in small groups.

Groups of parents are allocated depending on the reasons for the failure of their children.

The first group of parents (due to weakwilled upbringing, children do worse than they could). For this group of parents, the class teacher gives approximately the following recommendations:

To provide children with permanent and feasible tasks that is essential for the family economy. Students, performing these assignments, are taught to work systematically, to overcome the difficulties encountered, they actively form a will. Those who provide them with educational assistance in learning outside of school should refrain from untimely prompts, do not allow homework for the student himself. At the same time, it is necessary to ensure that the student himself finds the mistakes made or the course of solving the problem. If the student, after repeated independent attempts, does not cope with the task, then it is necessary not to suggest, but to direct his reasoning in the right direction, so that they lead to an independent solution of the cognitive problem. At the same time, the student should be tactfully required to exercise self-control (retelling the essence of the task, checking the correctness of the course of its solution, etc.). Properly provided educational assistance to students will teach them to overcome the difficulty encountered in the process of learning, educates independence and develops faith in their own strength and capabilities. Strong-willed education is associated with the formation of students' sense of duty and responsibility. Therefore, parents should present their children with a number of requirements and monitor their implementation. For example, you can do your homework at a certain time, set by the daily routine, and in a designated place for this purpose. At the same time, take 10-minute breaks every 45 minutes, observe the order of homework, be sure to exercise self-control; observe the daily routine, do physical exercises, regularly harden the body, etc. Students' compliance with the requirements set for them should be encouraged. The incentive measures should correspond to the degree of compliance with the requirements, i.e. the student should feel and be convinced that he is worthy of this encouragement or deserves blame. 
The personal example of parents and other family members, their attitude to their work and social duties, accuracy, loyalty to the word, respect for public opinion, etc. play a significant role in the education of the will, duty and responsibility of children. The relationships of adult family members should be imbued with a sense of duty to the collective, to society. In such cases, the strong-willed qualities of children are most favorably brought up.

The second group of parents (due to lack of discipline, children do less well than they could). Overcoming indiscipline begins with the establishment of a more favorable relationship between parents and children. To this end, parents are introduced to the age and psychological characteristics of younger adolescents, as well as techniques for establishing good relationships with them. They are given advice on how to change the previous style of communication with children, based on threats, categorical prohibitions, humiliation of the child, etc. In communication with parents, children should feel respect for them, love and care. The relationship of all family members should be positive. The family and the school must make the same demands on the children. If the student at home does not meet these requirements, then this should be reported to the class teacher, get qualified recommendations from him.

To overcome the negative influences of peers, informal groups, you must change the operating mode of unruly student, to give him all possible tasks at home, given his interests and inclinations, to determine the children's circle section at the place of residence or, if necessary, at a day care center.

Parents should use concrete examples to convincingly show the child the harmfulness of the path on which he found himself, explain the essence of the requirements and rules of behavior, the need to comply with them, both personally and socially. If the indiscipline of the student is associated with the inability to do homework, then parents should inform the school about this. In addition, it is necessary to organize the joint preparation of homework by children at the place of residence, as well as to provide them with the necessary practical educational assistance. It is very useful to encourage the participation of undisciplined children in social work, in the neighborhood, at school, in children's associations, in groups to check the implementation of the daily routine by students, etc.

Parents should require the preparation of homework at a certain time set by the daily routine, and in the workplace designated for this purpose, timely access to school and return home, etc. Such control actively educates students to be disciplined.

The third group of parents (children perform worse than they could, due to the negative influence of factors of the home environment). The class teacher gives the parents of these students approximately the following recommendations. The highly moral atmosphere of the family, friendly relations between its members, mutual respect, mutual assistance in household management, and the positive example of parents create the most favorable conditions for a good student's mood for learning, and contributes to successful learning: consistent, uniform requirements of parents for children; such a position of the student in the family, when his educational work is considered very important and necessary; proper stimulation of children in the family for the results of their studies (while not mixing encouragement with a kind of "bribery", as well as high demands with endless nagging, notation, rudeness, and sometimes rigidity in relation to the child). The stimulation should help the student to understand the significance of the teaching.

\section{MATERIALS AND METHODS}

Creating the necessary conditions for studying in the family (the presence of a workplace for children, a table, a chair, a bed, a wardrobe or a shelf for books, a table lamp, textbooks, teaching aids, educational supplies, etc.); improving the health and performance of 
children; expanding the cultural and general educational horizons of the student (the presence of a personal library, newspapers, magazines, radio, TV in the family; monitoring of extracurricular reading, visiting cinemas, museums; joint reading and discussion of books and articles, watching films and discussing them; conversations about the news of politics, science, technology, etc.); providing children with pedagogically correct educational assistance; monitoring the educational work of children (compliance with the daily routine; ensuring regular attendance of educational and extracurricular activities; tactful check of daily homework, if the student sometimes shows indiscipline in this regard; periodically review the diary and notebooks, check the accuracy and their design and systematic work in the classroom, the safety of textbooks); taking into account the real strength and capabilities of the student when presenting him with requirements for improving academic performance; systematic accounting of the time spent by students on preparing homework in individual subjects and in general.

If the time spent is higher than the norm established by the Charter of the school, this should be reported to the class teacher. The student must do their homework on the day they receive it, and repeat what they have learned before the upcoming lesson; observe the order of homework, ensure that the student prepares lessons at the same time, set by the regime of the day, at the same workplace. During the student's homework, extraneous noises (radio, TV, small children, adult conversations, etc.) should be excluded. It is necessary to ventilate the room well, do not distract with household errands. Make sure that children take a 10-minute break every 45 minutes of class. During the break, you can instruct children to perform small household tasks, you should encourage them to perform physical exercises. It is important to alternate between written homework and oral homework (Russian, natural science, mathematics, history, etc.). The student should start solving the problem and performing the exercises only after he has learned the corresponding theoretical section from the textbook. In case of difficulties in solving problems, it is necessary to repeat the theory once again and take up the solution again.

Parents should ask children coming from school not about grades, but what new things they learned today, what useful things they did for the team, the school, how he and his friends answered the teachers' questions in class, whether the teachers were satisfied with their answers, etc. The marks can be found in his diary. If a student has received an unsatisfactory mark, then parents should talk to the class teacher and subject teachers, to identify its causes. Then-explain them to the student and implement the system of measures proposed by the teachers in the family. A skillful combination of parental benevolence, the desire to help with high demands most often resolves the situation: "getting a deuce".

The fourth group of parents (due to reduced performance, children perform worse than they could).

With this dominant, parents should do something like the following: First of all, pay attention to the organization of the student's daily routine, systematically monitor compliance with each of its elements. Especially: regular performance of morning exercises by the child (morning gymnastics for teenage children consists of 8-10 exercises): preparation of homework; stay in the fresh air; timely reception and go to bed (sleep for children of grades 4-5 should be at least 9-10 hours). It is also necessary to take measures for the regular hardening of children in the family (organization of the correct use of sun baths, water procedures); the workplace of the student in the family must meet hygienic standards. The height of the table from the floor should be $68 \mathrm{~cm}$, and the chair $41 \mathrm{~cm}$. If the student works at a common table, then the difference between the height of the table and the height of the chair should be a maximum of $27 \mathrm{~cm}$ and a minimum of $21 \mathrm{~cm}$. The student's corner is best placed closer to the window. Natural light should fall from the left. Provide children with a table lamp. The lamp is placed to the left of the student. An electric light 
bulb with a power of 40-50 watts should be covered with a lampshade so that the light from it does not get into the eyes and does not blind the child); ensure silence during the preparation of classes; provide educational assistance if necessary; organize a rational alternation of work and rest for children after classes and on Sundays; take care of timely medical examinations; treatment of diseases; together with children to go on an excursion to nature, on hiking trips; encourage children to take part in physical education classes, participate in sports games, hiking, etc.

The fifth group of parents (children perform below their capabilities due to a negative attitude to learning).

The negative attitude of the student to the teaching is overcome by the formation and development of positive motives of the teaching. To do this, parents are given approximately the following recommendations:

1) Parents should form a favorable psychological atmosphere in their relationships with children;

2) To form an interest in teaching and a belief in its necessity, an understanding of personal and social significance, and the need for teaching.

To solve these two tasks, it is very important: to achieve a favorable relationship between parents and children, to refuse threats, punishments, work-outs, reproaches, disregard for their interests; to believe in the student, to help him get on the right path, to forget his mistakes, mistakes in behavior, impertinence, rudeness; to help him start all over again, etc.

Parents, siblings, and other adult family members should explain and use concrete examples to show children the need for a diligent attitude to teaching. In the process of life itself, they convincingly show the place and role of knowledge by the example of their activities, neighbors and acquaintances in the neighborhood, other workers and collective farmers. Conversations in a relaxed atmosphere also contribute to the children's awareness of the personal significance of the teaching. To show students the social significance of the teaching, parents and other adult family members should talk with children about the role of science in the development of the economy, culture, and life of the workers of a given village, city, district, region, republic, and country as a whole, and in increasing labor productivity through rationalization and invention. In addition, it is useful to visit with children such institutions and organizations where the main professions especially attract the attention of the student. There you can directly show the children the need (in mastering the profession that interests them and in further successful work in this profession) of knowledge on the subject that they do not like.

In addition, it is necessary to determine the place of the student in the family with his educational affairs; to look at the educational work of children as the most important, the most important thing in their life; it is necessary to react accordingly to the child's educational successes and rejoice with him, and to experience failures in learning together, to maintain self-confidence in him.

It is important to create favorable conditions for children's studies in the family, the parents' demands on children should be combined with systematic control over the educational work and pedagogically correct educational assistance; provide educational assistance; provide educational assistance in a way that does not infringe on the independence of the student; it is necessary to encourage the success of children in learning and their desire for good learning; correctly use methods of encouraging and condemning the results of study and the level of compliance with academic discipline.

If the student has a negative attitude to any subject, for example, to mathematics, then parents should talk with their children about the meaning, role and place of mathematics in the life and practical activities of each person, in the development of human society. It is useful to read and discuss together with children the literature of mathematical content, especially books devoted to the life and work of mathematical scientists, 
entertaining mathematics, etc. For the achieved success in mathematics, you can give books with mathematical content, various games for training geometric imagination and logical thinking, a set of portraits of outstanding mathematical scientists, and offer to use these portraits to prepare a beautiful stand for the school. It is necessary to organize a competition in the family for fast calculation (orally and in writing), while using elements of entertaining mathematics; give children instructions for calculating and making certain models, as well as work with them together. For example, you can instruct children to calculate the family expenses for one day, for a week, for a month, or to observe the growth of young plants in the garden; in the front garden; together with the children, make geometric shapes from a textbook and present them to the school's mathematics office (in the presence of students, teachers, parents). Parents should actively participate in the preparation and conduct of mathematical matinees, evenings, in the management of clubs, etc. Encourage the participation of their children in such activities; in the family circle, systematically express good feedback to the math teacher and in general to the teachers of the school. Such actions of parents not only destroy the negative attitude of children to mathematics, but also arouse interest in it.

If the negative attitude of children is associated with poor development, low level of skills of educational work, indiscipline, low level of efficiency, etc., then the dominant one is determined from the system of reasons for the negative attitude and work is being done to overcome this reason. The above recommendations are given to overcome some of these reasons, and the rest will be discussed later.

The sixth group of parents (due to the weak development of thinking, children do worse than they could).

Proper educational assistance provided by parents will lead to the development of children's thinking. When providing assistance, fathers and mothers should strive to ensure that children themselves find the mistake made in the course of solving the problem, i.e., independently perform homework. To achieve this, parents should provide educational assistance in the form of substitution of the child's independence, tips, at the first difficulties of preparing homework for children delay the development of their thinking. If children are provided with the minimum necessary doses of educational assistance, then they develop independent work skills and strongwilled qualities, at the same time actively developing thinking.

\section{RESULT AND DISCUSSION}

Parents should demand that their children, when preparing homework, first study the theoretical part of the educational material in a meaningful way, and then begin to solve the problem or perform exercises. At the same time, the student must rely on theoretical material, i.e. apply it in practical work. This is the main way of developing the student's thinking, and an important principle of eliminating gaps in knowledge. Achieving a systematic, accurate and meaningful preparation of homework by children also actively develops their thinking. For him, when solving the problem, you must adhere to the following rules. Carefully read the text, think about what it is about, highlight the main, essential thoughts, understand them. And then retell what you read in parts. Then re-read the whole text again, make sure that everything is clear, retell it again, and answer the questions raised. Check the correctness of the solution of the problem.

Parents can teach children to ask questions to teachers, classmates, etc. for this purpose, adult family members, helping children in the preparation of homework, together with them make up several questions with the help of the main, essential in the material being studied. Encourages children to answer these questions independently. Gradually, children will learn to independently compose such questions and answer them. Children can ask the teacher for an explanation of the questions made at home. This work contributes to teaching kids to plan an 
upcoming answer at a lesson in the form of questions, logical order of presentation in lesson drawn house plan, ask questions.

It is interesting and useful in the family to use techniques that help speed up the pace of work (reading, writing, calculating and sketching) of children. For example, if a child rewrites a text of 30 words in 3.5 minutes, you can ask him to rewrite this amount of text in 3 minutes, if a student reads a text of 50 words in one minute, advice him to read a text of 55 words in a minute. It is more useful to suggest drawing a certain part of the drawing or drawing in a certain minimum of time. To speed up the pace of calculation, it is necessary to achieve a good knowledge of the multiplication and division tables, rational methods of written and oral calculation, etc. You can also organize a competition in the family among the children-students on the fast pace of work. This will help teach them how to read, calculate, write, and sketch correctly and quickly. Parents should read books together with their children, watch TV shows, go to museums, movies, theaters, and listen to radio programs that correspond to the age of children. Discuss it together with them. Using the training of geometric imagination and logical thinking games such as "Pentomino", "Constructor", etc., you can build various shapes. Helping children to prepare various visual aids on the condition of the problem, it is necessary to use more widely in the family elements of entertaining mathematics, materials of the magazine "Family and School" under the heading "Together with children", "Our Home" , etc. The implementation of this system of measures in the family contributes to improving the level of development of children's thinking.

The seventh group of parents (children perform poorly than they could, due to gaps in the skills of educational work).

Cool the leader in this group of parents has a conversation about the role and importance of the mode of the day in the life and human activities and also gives recommendations as to enforce his children; on the order of homework; about cooking at home jobs in the day of receipt, and briefly to repeat learned before the upcoming activity; the formation of children the skills to make a plan of study material, the response plan the next lesson plan solve the problem; about selfcontrol: control the degree of assimilation of theoretical material, the correct execution of the exercises and solutions of the problem; about ways to increase the pace of reading, writing, calculating, sketching; about instilling skills to work with a book.

Subject teachers use concrete examples to show the parents of students the techniques of drawing up a plan, exercising self-control and speeding up the pace of work.

The eighth group of parents (due to gaps in knowledge, children do less well than they could).

Parents should be familiarized in general terms with the content of the current curriculum (basic provisions, new concepts, rules, terms, etc.).

The subject teacher should familiarize parents with the goals, objectives and methods of setting homework, and equip them with rational methods of providing educational assistance to children.

Parents are explained the techniques of skilful control over the systematic, meaningful and, if possible, independent performance of homework to overcome gaps in knowledge, the solid assimilation of new educational material; systematic school alerts about difficulties encountered (in the allocation of the main material of the studied material, in a special study and analysis of the problem, the allocation of data and unknown to the conditions of the problem in determining the link between data and the unknown, in drawing up the plan for the upcoming answer at a lesson in the exercise of self-control, etc.) children in preparing homework; education of children in the right attitude to additional classes; control over the regular attendance of children in educational classes. If children miss school classes due to illness or other reasons, then it is necessary to support and assist the school in implementing a system of measures to overcome the situation in the gaps in children's 
knowledge (in overcoming the reason for missing school classes, in organizing educational assistance to sick children from classmates, monitoring the implementation of individual additional tasks of the teacher on the topics of missed lessons, ensuring the participation of children in additional classes, assigning children to a well-performing student, the asset of parents, etc.).

\section{CONCLUSION}

The implementation of the described system of measures by parents and other persons providing educational assistance to children outside of school helps teachers to prevent and overcome gaps in the knowledge of students.

In short, this is how class teachers organize work with the parents of students:

1) provides a creative, innovative approach to their professional activities;

2) provides an informed approach to working with parents and the content of their education;

3) raise parents' awareness of education;

4) brings the cooperation of the school and the family to a qualitatively new level;

5) increases the prestige and social status of classroom teachers;

the effectiveness of the training and education of students.

\section{LIST OF REFERENCES}

[1] Law of the Republic of Uzbekistan "On Education" dated September 23, 2020, OPQ-637.

[10]
[2] Decree of the President of the Republic of Uzbekistan No. PF-6108 dated November 6, 2020 "On measures to develop education and science in a new period of development of Uzbekistan.

[3] "The President of the Republic of Uzbekistan" On measures to improve the spiritual, moral and physical development of youth, raising the education system to a qualitatively new level "2018 - Resolution No. PQ-3907 ofAugust 14.

[4] Resolution of the President of the Republic of Uzbekistan No. PP-3931 dated September 5, 2018 "On measures to introduce new management principles in the public education system.

[5] "Minutes of the qualifying meeting of the President of the Republic of Uzbekistan with public educators. 23 August 2019.

[6] Message from the President of the Republic of Uzbekistan ShavkatMirziyoyev to the OliyMajlis dated December 29, 2020.

[7] BabanskyYu.K. Optimization of the educational process: (Method. Basics). $-\mathrm{M}$ : Education, 1982. - 192 p.

[8] P.Z.Davronov Joint activities of the school and seven to prevent academic failure in grades IV-V. ...CandidateofPedagogicalSciences. - M., 1982 .-- 255 p.

[9] Tuychieva R. Japanese education begins with January 1, 2020 